\title{
O trabalho de assistentes sociais no enfrentamento à violência sexual contra crianças e adolescentes: eis a questão
}

\author{
The work of social worker in the fight against sexual violence against \\ children and adolescents: this is the question
}

Juliane Lucas Viegas Pachecoํㅡㄹ Ângela Maria Pereira da Silva ${ }^{1}$, Gehysa Guimarães Alves ${ }^{1}$, Tainara da $\operatorname{Rosa}^{1}$

\begin{abstract}
RESUMO
Trata-se de um relato de experiência teórico e prática oriunda dos Estágios em Serviço Social, realizados no âmbito da política de assistência social, realizado entre os anos de 2020 e 2021. Contextualizaremos acerca do processo de trabalho do assistente social no atendimento a crianças e adolescentes em situação de violência sexual através do Serviço de Proteção e Atendimento Especializado a Famílias e Indivíduos, executado no CREAS de São Leopoldo, no Rio Grande do Sul. Utilizou-se o grupo como um dos instrumentos de trabalho capazes de potencializar o vínculo entre as usuárias e essas com a autora. Tal campo apresentou-se como um serviço com demandas que revelam a banalização histórica e cultural em torno da violação de direitos de crianças e adolescentes expressa através da violência sexual. Assim como trouxe à tona a importância da legitimação do Estatuto da Criança e do Adolescente. Essa problemática ganhou mais evidência, à medida que vivenciamos o isolamento social em tempos pandêmicos. Portanto, trata-se de um tema relevante para discussão e para subsídio para a construção de novas práticas profissionais de assistentes sociais no enfrentamento dessa questão social, discutido a partir do método do materialismo dialético. Os principais resultados evidenciaram que esse grupo possibilitou o fortalecimento de vínculos, da identidade, o empoderamento através da informação assertiva, autonomia e cidadania.
\end{abstract}

Palavras-chave: Abuso; Exploração sexual; Direitos; Assistência Social.

\begin{abstract}
This is a report of theoretical and practical experience arising from Internships in Social Work, carried out within the scope of social assistance policy, carried out between 2020 and 2021. We will contextualize about the work process of the social worker in the care of children and adolescents in situations of sexual violence through the Service of Protection and Specialized Assistance to Families and Individuals, carried out at CREAS in São Leopoldo, Rio Grande do Sul. The group was used as one of the work instruments capable of enhancing the bond between the users and those with the author. This field was presented as a service with demands that reveal the historical and cultural trivialization around the violation of the rights of children and adolescents expressed through sexual violence. It also brought to light the importance of legitimizing the Child and Adolescent Statute. This problem has gained more evidence, as we experience social isolation in pandemic times. Therefore, it is a relevant topic for discussion and support for the
\end{abstract}

\footnotetext{
${ }^{1}$ Instituição de afiliação: Universidade Luterana do Brasil - Ulbra

E-mail: tainaradarosa7@gmail.com
} 
construction of new professional practices of social workers in facing this social issue, discussed from the method of dialectical materialism. The main results showed that this group enabled the strengthening of bonds, identity, empowerment through assertive information, autonomy and citizenship.

Keywords: Abuse; Sexual exploitation; Rights; Social assistance.

\section{INTRODUÇÃO}

Parto do ingresso no Centro de Referência Especializado de Assistência Social CREAS, mais especificamente no Serviço de Proteção e Atendimento Especializado a Famílias e Indivíduos - $\mathrm{PAEFI}^{2}$, no município de São Leopoldo/RS. O CREAS conforme a Política Nacional de Assistência Social - PNAS (2004) corresponde a Proteção Social Especial de Média Complexidade. Ainda, segundo a Tipificação Nacional de Serviços Socioassistenciais (2009); cabe ao referido serviço prestar apoio, orientação e acompanhamento às famílias que se encontram em maior risco e vulnerabilidade social, ou seja, no que se refere à violação de direitos.

Ademais, especificamente com os usuários, famílias e comunidades que vivenciam o agravamento das expressões da questão social, tais como: violência física, psicológica; violência sexual: abuso/exploração sexual; negligência e abandono; exploração do trabalho infantil; entre outras. Neste serviço, são diversas as demandas que chegam advindas de situações de violações de direitos de usuários e suas famílias. Todavia, durante a realização dos estágios, a violação que se sobrepôs no PAEFI foi a violência sexual contra crianças e adolescentes.

Tendo definido este como o objeto de intervenção, relacionamos com o Serviço Social a partir do seu objeto de trabalho, a questão social, entendendo que a mesma está intrinsecamente ligada às diversas expressões da violência resultantes do sistema capitalista. A atuação de assistentes sociais no enfrentamento de violências, em qualquer de suas expressões, é pauta frequente no cotidiano profissional e nos espaços de controle social.

\footnotetext{
2 Definido pela Tipificação Nacional dos Serviços Socioassistenciais como: "Serviço de apoio, orientação e acompanhamento a famílias com um ou mais de seus membros em situação de ameaça ou violação de direitos". (BRASIL, 2009)
} 
Portanto, o objetivo deste artigo é contextualizar acerca do trabalho de assistentes sociais no CREAS no atendimento a crianças e adolescentes em situação de violência sexual. Numa perspectiva de contribuir com a produção de conhecimentos acerca do tema a partir da experiência de estágio em serviço social. Tendo base a corrente teórica dialético crítica e embasamento em autores do Serviço Social como Iamamoto (2015), Faleiros (2007), Minayo (2006); Guerra (2011), entre outros.

O artigo está estruturado da seguinte forma: 1) situamos o/a leitor/a sobre as expressões da questão social que impactavam a vida das usuárias incluídas no grupo; 2) contextualizamos acerca da Política Nacional de Assistência Social/ SUAS, bem como sobre a Tipificação Nacional dos Serviços Socioassistenciais; 3) apresentamos os elementos constitutivos da profissão por meio do projeto de intervenção executado nos estágios obrigatórios em Serviço Social, por fim traçamos algumas considerações.

\section{METODOLOGIA}

Trata-se de um relato de experiência ${ }^{3}$ do processo de trabalho realizado no decorrer dos Estágios Obrigatórios em Serviço SociaI I e II, em especial, com relação ao projeto de intervenção intitulado "Conversando sobre Abuso Sexual" a partir das dimensões da profissão. Esse estudo também faz parte de uma pesquisa documental com abordagem qualitativa. Segundo Gil (2008), não se deve considerar somente documentos escritos para fins de pesquisa científica, mas também qualquer objeto que possa contribuir na investigação do fenômeno estudado. No que tange a abordagem, Minayo (2017) defende que a qualitativa busca a intensidade, ou seja, a qualidade do fenômeno estudado, e também se destaca no que tange a dimensão sociocultural dos fenômenos, uma vez que ela se expressa através das crenças, comportamentos e costumes das jovens atendidas no CREAS.

No que se refere a documentação, valho-me dos registros em diário de campo, análise institucional, observação participante, além da coleta de dados a partir de informações da Vigilância Socioassistencial, da avaliação e das narrativas das participantes do grupo. Também, dos registros dos encontros grupais no prontuário das

\footnotetext{
3 Observa-se neste item, a Resolução do Conselho Nacional de Saúde - CNS n 510 de 2016, Art. $1^{\circ}$, Parágrafo Único, que determina: "Não serão registradas nem avaliadas pelo sistema CEP/CONEP: VII pesquisa que objetiva o aprofundamento teórico de situações que emergem espontânea e contingencialmente na prática profissional, desde que não revelem dados que possam identificar o sujeito." (BRASIL, 2016).
} 
usuárias, reuniões entre a acadêmica/estagiária com a respectiva supervisora de campo para redefinição de temas e materiais necessários a cada intervenção realizada.

Cabe situar que o respectivo campo de estágio fica localizado em São Leopoldo/RS, município com 103,009km² de extensão e 240.378 habitantes, faz parte da região metropolitana de Porto Alegre (IBGE, 2021). O CREAS, por sua vez, fica situado na Rua Primeiro de Março, no 237, Bairro Centro deste município desde o ano de 2016. Ressalta-se que até meados do ano de 2007, a Secretaria Municipal de Assistência, Cidadania e Inclusão Social (SACIS) conveniou com uma Organização Nãogovernamental a execução do Programa Sentinela ${ }^{4}$, que atendia crianças e adolescentes em situação de abuso e violência sexual. Contudo, após a SACIS aderir a PNAS, a Diretoria de Proteção Especial elaborou um projeto que fora encaminhado para aprovação no Conselho Municipal de Defesa dos Direitos da Criança e do Adolescente COMDEDICA, e que, com a parceria financeira da Petrobrás, tornou possível estruturar o CREAS, que assumiu a execução do respectivo programa federal, passando a integrarse como um serviço denominado PAEFI.

Com o ingresso no CREAS, optou-se pelo grupo como instrumento de trabalho de assistentes sociais na execução do projeto de intervenção, porém esse aprofundamento será realizado no subitem "O grupo como instrumento de trabalho do assistente social no Serviço de Proteção e Atendimento Especializado a Famílias e Indivíduos”. Registrou-se neste grupo a participação de quatro usuárias, uma com 12 anos de idade, a sua irmã com 15 anos, a mãe dessas com 40 anos, e uma jovem de 18 anos sem vínculo familiar com as três. Exceto a adulta, as demais se encontravam em serviço de acolhimento institucional no momento da intervenção. $\mathrm{O}$ grupo teve um total de 4 encontros, sendo que as mesmas participaram assiduamente das intervenções.

Importante mencionar os princípios éticos na inter-relação com as usuárias com base no Código de Ética de Assistentes Sociais (Lei 8.662/93 de Regulamentação da Profissão), visto que o sigilo profissional foi resguardado (BRASIL, 1993). Inclusive, levando em consideração a delicadeza das narrativas trazidas pelas mesmas, os dados das participantes serão mantidos em anonimato ${ }^{5}$.

\footnotetext{
${ }^{4}$ Programa do Governo Federal que visa prevenir e atender crianças e adolescentes vítimas de violência e exploração sexual. (São Leopoldo, 2006).

$5 \mathrm{Na}$ perspectiva de preservar o anonimato das participantes do grupo, suas identidades foram mantidas em sigilo.
} 
No que se refere à forma de análise dos dados, conforme Gil (2002), objetiva organizar e sumariar os dados de forma tal que possibilitem o fornecimento de respostas ao problema proposto para investigação. E para Lakatos e Marconi (2002), é a tentativa de evidenciar as relações existentes entre o fenômeno estudado e outros demarcadores sociais (gênero, classe social, grupo étnico-racial, geracional, entre outros).

A corrente teórica desse artigo é o materialismo dialético crítico, que busca explicar os diversos fatores que produzem determinada realidade. Para desvendar a realidade o assistente social deve partir das categorias centrais: historicidade, totalidade e contradição (LOPES, 2010). Tais categorias permitem apreender a violência sexual contra crianças e adolescentes. A totalidade leva em conta a complexidade que envolve tal violência e seu acometimento na sociedade. A historicidade revela os diferentes contextos econômicos, sociais, culturais e históricos do fenômeno. Por fim, a partir das relações de contradição, é possível desenvolver uma análise crítica buscando elementos que possam subsidiar a superação da violência ocorrida.

\section{A VIOLAÇÃO DE DIREITOS DE CRIANÇAS E ADOLESCENTES: EIS UMA DAS EXPRESSÕES DA QUESTÃO SOCIAL}

Desde o período de colonização do Brasil, do século XIV até XIX, deflagrou-se uma série de violações de direito do público infanto juvenil, expressa no trabalho precoce, abusos, maus tratos, negligência, violências, entre outros. Rizzini (1996) revela que a trajetória da não-cidadania das crianças brasileiras tem origem no período colonial.

Sabemos, portanto, que o desenvolvimento do país é historicamente ligado a escravidão, a dominação do mais forte pelo mais fraco, a opressão e a violência. Conforme Priore (2012, p. 10) "foi entre pais, mestres, senhores e patrões, que pequenos corpos tanto se dobraram a violência, às humilhações, à força". Advinda dessa construção social, está implícita a ideia de que os mais fortes podem explorar e dominar segmentos sociais tidos como vulneráveis (Faleiros, 2007). Isso ocorre pelas representações e comportamentos compartilhados na sociedade sobre determinados grupos sociais, inclusive, com relação às intersecções de raça/cor, gênero, classe, grupos etários, deficiências, entre outros demarcadores.

\footnotetext{
Até outro dia parecia normal que as crianças que viviam no hemisfério sul do planeta (em geral países pobres, tidos como "atrasados") passassem sua infância e adolescência no trabalho pesado e não fossem à escola. Nada demais se apanhassem e fossem exploradas - nem se considerava isso um abuso e muito menos uma "violação de seus direitos. (FISCHER, 2010, p. 4).
} 
Constata-se a relação tênue com os diversos tipos de abuso, sobretudo o sexual, contra crianças e adolescentes ao longo do tempo. Essa problemática perpetua-se na história das crianças de ambos os sexos em várias partes do mundo, embora os avanços no aparato legal desse segmento, na condição de cidadão com direitos e deveres aparentemente reconhecidos no Brasil.

\begin{abstract}
A história sobre a criança feita no Brasil, assim como no resto do mundo, vem mostrando que existe uma enorme distância entre o mundo infantil descrito pelas organizações internacionais, por organizações não governamentais ou autoridades, e aquele no qual a criança encontra-se quotidianamente imersa. (PRIORE, 2012, p. 233)
\end{abstract}

Com o advento do Estatuto da Criança e do Adolescente - ECA (BRASIL, 1990), este passa a ser instrumento de consolidação de direitos de crianças e adolescentes. Define em seu Art. 15 direito à liberdade, ao respeito e à dignidade como pessoas humanas em processo de desenvolvimento e como sujeitos de direitos civis, humanos e sociais garantidos na Constituição e nas leis. Consta ainda que, embora os adultos/pais sejam socialmente responsáveis pelas crianças e adolescentes, é preciso ter clareza de que os mesmos são sujeitos de direitos legítimos que devem ser priorizados. Portanto, a violência contra crianças e adolescentes, de qualquer tipo, é uma relação de poder baseada em pesos desiguais. Para Azevedo e Guerra (2001, p. 33)

Todo ato ou omissão, praticado por pais, parentes ou responsáveis contra crianças e/ou adolescentes que, capaz de causar dano físico, sexual e/ou psicológico à vítima, implica numa transgressão do poder/dever de proteção do adulto e, por outro lado, numa coisificação da infância, isto é, numa negação do direito que crianças e adolescentes têm de ser tratados como sujeitos e pessoas em condição peculiar de desenvolvimento.

Além disso, essas violências ocorrem geralmente no âmbito intrafamiliar, perpetuada por um membro da família ou alguém próximo a criança e adolescente. Entendemos, portanto, que a violência contra crianças e adolescentes é também uma expressão da violência estrutural, bem como de suas características socioeconômicas e políticas de uma sociedade capitalista findada na produção da exclusão social e na privação de direitos fundamentais, resultando em uma sociedade injusta e não igualitária (MINAYO, 2001). Para a autora, essa violência consiste em usar de força, poder ou privilégios a fim de dominar outras pessoas, grupos ou coletividades. É nesse sentido que as manifestações da questão social na vida dessas crianças e adolescentes usuários/as das políticas, programas e projetos sociais apresentam-se como um objeto de trabalho de assistentes sociais na política de Assistência. 
Na medida em que através de uma breve análise de documentos da Vigilância Socioassistencial, foi possível constatar que boa parte das crianças e adolescentes atendidas eram oriundas de situação de abuso e/ou exploração sexual, majoritariamente pelo sexo feminino. Nesta sociedade, em que as relações de gênero pressupõem desigualdades de poder e direitos, o privilégio masculino é evidenciado em todos os aspectos de nossa vida (SIQUEIRA, 2009). Dessa forma, entendendo a "questão social como o conjunto das expressões das desigualdades da sociedade madura" (IAMAMOTO, 1998 p. 27), e sabendo que é neste campo que se dá o trabalho do assistente social, devendo intervir nas múltiplas expressões da questão social conforme experenciada pelos sujeitos em suas vidas quotidianas (IAMAMOTO, 1998), que as vulnerabilidades e fragilidades advindas das situações de abuso sexual tornaram-se o objeto do projeto de intervenção intitulado 'Conversando sobre abuso sexual" realizado no CREAS de São Leopoldo.

Ao longo da rotina de trabalho da equipe do CREAS, observamos que o segmento infanto juvenil encontra-se em maior grau de risco e vulnerabilidade social à medida que suas famílias, também, estão desassistidas do sistema de proteção social. Ou seja, são indivíduos, famílias e comunidades geralmente domiciliadas em espaços periféricos, com dificuldade de acesso aos bens e serviços sociais disponíveis na rede intersetorial. Isso ficava evidenciado na falta de adesão aos serviços do CREAS por questões econômicas e financeiras, de deslocamento, também pela morosidade entre a violação do direito e o ingresso da família e do usuário em atendimento. Esses fatores somam-se ao constrangimento de abrir detalhes mais íntimos das relações de convivência da família, principalmente quando o violador faz parte do núcleo familiar.

A violência sexual é entendida por Faleiros (2007, p. 38), como:

Uma violação dos direitos humanos universais e dos direitos peculiares à
pessoa em desenvolvimento: direito à integridade física e psicológica, ao
respeito à dignidade, ao processo de desenvolvimento físico, psicológico,
moral e sexual sadio e a proteção integral. A violência sexual no âmbito
familiar é uma violação ao direito a sexualidade segura e a convivência familiar
protetora. Ainda para o autor, essa violência é produzida pela desigualdade nas relações de poder e de gênero, que é manifestada em abuso e exploração sexual através da violação dos direitos sexuais e reprodutivos, neste caso, de crianças e adolescentes. Ainda há de se levar em consideração que a exposição ao abuso sexual na infância está associada a 
prejuízos em longo prazo, representando fator de risco biopsicosocial e emocional, tais como: depressão, ideação suicida, ansiedade, estresse, entre outros (LIRA et al, 2017). Tais repercussões devem ser o foco da equipe interdisciplinar do CREAS, que deve lidar e ampliar acesso aos serviços e políticas sociais às meninas, adolescentes e mulheres em situações de violência sexual.

Nessa perspectiva de atendimento, foi planejado um grupo multifamiliar para crianças, adolescentes, jovens e suas famílias, abordando a temática do abuso sexual. Dentre os atendimentos realizados constatou-se que as participantes do grupo tinham ausência da figura paterna, com isso, as mesmas permaneciam longas horas do dia sozinhas, pois as genitoras precisavam sustentar a si e os demais membros da família. Esse arranjo familiar, somado a outros fatores favoreceram a violação dos seus direitos, a exemplo: ausência de informação, falta de diálogo, uso de substâncias psicoativas, abuso de álcool, distúrbios, etc. Nessa lógica, esse público é tido em desvantagem pelo seu estágio de desenvolvimento biopsicossocial e emocional, o que leva, por vezes, ao não reconhecimento como sujeito de direitos, e ainda como objeto de dominação por parte de seus abusadores. Essa problemática tem ganhado espaço de debate, ao mesmo tempo que passa a ter maior incidência em tempos pandêmicos.

Importante salientar o impacto da pandemia nas denúncias de violência sexual de crianças e adolescentes. Segundo dados do Disque 100 (2020) foram 14.621 registros no primeiro ano da pandemia. Em 2021, até 12 de maio, o Disque 100 registrou mais de seis mil denúncias de violência sexual contra o público infanto juvenil.

Frente a isto, e tendo como objeto essa expressão da questão social no CREAS de São Leopoldo, o abuso e à exploração sexual representam um desafio no cotidiano de trabalho de assistentes sociais, evidenciando a necessidade de pensarmos novas estratégias de enfrentamento a essa problemática.

\section{POLÍTICA DE ASSISTÊNCIA SOCIAL: UMA BREVE CONTEXTUALIZAÇÃO APÓS A CONSTITUIÇÃO FEDERAL DE 1988}

A Constituição Federal de 1988 (CF/1988) foi um marco na política de Assistência Social, pois passou a ser reconhecida como direito a quem dela necessitar e 
como dever do Estado, compondo conforme o Art. $194^{6}$, o tripé da Seguridade Social. A regulamentação dos artigos 203 e $204^{7}$ da CF/1988, se deu através da promulgação da Lei Orgânica de Assistência Social (LOAS), em 1993. Contudo, a efetivação dessa política ocorreu somente em 2004, com a aprovação da Política Nacional de Assistência Social e a Norma Operacional Básica (NOB/SUAS), materializando o texto constitucional e da LOAS, através de conceitos que baseiam a consolidação do Sistema Único de Assistência Social (SUAS), em 2005.

O SUAS, tendo como base os princípios da PNAS (universalização dos direitos sociais; respeito a dignidade do cidadão e a sua autonomia; centralidade na família; a convivência familiar e comunitária, etc.) estruturou-se por níveis de proteção social básica, média e de alta complexidade. Salienta-se que, a partir do SUAS, surge a "profissionalização" da política, que passa a adotar procedimentos teóricos e técnicos no que se refere a organização dos atendimentos à população. Esse processo resulta na tentativa de ruptura do assistencialismo, clientelismo e imediatismo.

Contudo, embora os avanços advindos da CF/1988, LOAS, PNAS/SUAS, o ideário neoliberal iniciado na década de 1990 impediu a efetivação da política como um todo, tornando-a de cunho focalista e compensatório. Esse contexto tem impactos prejudiciais na sociedade, causando um acirramento das expressões da questão social (BEHRING; BOSCHETTI, 2011). Este é o resultado do neoliberalismo no Brasil e as novas configurações do Estado como agente regulador das Políticas Sociais, que segue os ditames do Banco Mundial e do Fundo Monetário Internacional (FMI). Se de um lado avançamos no reconhecimento de direitos que permite trazer para a esfera pública a questão das desigualdades, do outro temos o Estado em uma lógica controversa, no qual assume os preceitos de política econômica neoliberal, que hoje vigora a maioria dos países da América Latina, sem qualquer limitação dos mecanismos do mercado (SANTOS, 2002).

Nesse contexto, é importante salientar que a política social no sistema capitalista não é capaz de reverter o quadro das desigualdades econômicas, políticas, culturais e

\footnotetext{
6 Art. 194. A seguridade social compreende um conjunto integrado de ações de iniciativa dos Poderes Públicos e da sociedade, destinadas a assegurar os direitos relativos à saúde, à previdência e à assistência social (BRASIL, 1988).

${ }^{7}$ Art. 203. A assistência social será prestada a quem dela necessitar, independentemente de contribuição à seguridade social (BRASIL, 1988) Art. 204. As ações governamentais na área da assistência social serão realizadas com recursos do orçamento da seguridade social (BRASIL, 1988).
} 
sociais, nem tão pouco é sua função. Contudo, debater e lutar pela sua materialização na vida da população é um compromisso ético político da categoria profissional. Essa discussão envolve investimentos públicos capazes de impactar satisfatoriamente as condições de vida e de trabalho de seus usuários, bem como as condições de trabalho das equipes implicadas. Isso exige um processo de caráter coletivo, de socialização da política e de organização dos sujeitos políticos. Sendo assim, "se faz necessário um maior investimento na participação popular através da capacitação de conselheiros objetivando um controle social mais efetivo". (BEHRING; BOSCHETTI, 2011, p. 190)

Conforme mencionado anteriormente, a PNAS tem afiançadas níveis de proteção, na tentativa de resistir e enfrentar o desmonte das políticas sociais, bem como garantir os direitos de seus usuários. A proteção social básica é "destinada à população que vive em situação de vulnerabilidade social em decorrência da pobreza, privação ou fragilização de vínculos" (BRASIL, 2004, p. 33). No município de São Leopoldo a Política de Assistência Social na proteção social básica dispõe de cinco Centros de Referência de Assistência Social ${ }^{8}$ (CRAS), localizados em territórios geograficamente tidos com maior índice de vulnerabilidade social.

É importante evidenciar ainda duas categorias muito utilizadas pela PNAS: a vulnerabilidade social e o risco social. A PNAS não traz especificamente o conceito de vulnerabilidade social, mas aponta que:

\begin{abstract}
As situações de vulnerabilidade podem decorrer: da pobreza, privação, ausência de renda, precário ou nulo acesso aos serviços públicos, intempérie ou calamidade, fragilização de vínculos afetivos e de pertencimento social decorrentes de discriminações etárias, étnicas, de gênero, relacionadas à sexualidade, deficiência, entre outros, a que estão expostas famílias e indivíduos, e que dificultam seu acesso aos direitos e exigem proteção social do Estado. (BRASIL, 2012, p. 12)
\end{abstract}

Portanto, as situações de vulnerabilidade não prevenidas ou enfrentadas tendem a se tornar situações de risco. As situações de risco, por sua vez, tendem a serem aquelas em que os indivíduos e/ou famílias têm seus direitos violados. Logo, uma situação de vulnerabilidade não conduz necessariamente ao risco, pois fatores como a proteção social podem atenuar tal condição. Contudo, a vivência de risco pode propiciar novas vulnerabilidades, em um processo que acaba por fragilizar ainda mais as famílias e indivíduos. (BRASIL, MDS, 2018)

8 Composto por: CRAS Centro, CRAS Leste, CRAS Norte, CRAS Oeste e CRAS Nordeste. 
No que se refere a proteção social especial, "destina-se as famílias e indivíduos que se encontram em situação de risco pessoal e social em decorrência de violações de direitos, como abandono, maus tratos, abuso sexual, situação de rua, entre outras“" (BRASIL, 2004, p. 37). A proteção social especial subdivide-se em proteção social especial de média e de alta complexidade.

Nesse artigo aprofundaremos sobre a proteção social especial de média complexidade representada pelo CREAS, respectivo campo do estágio. Consta no Caderno de Orientações Técnicas: Centro de Referência Especializado de Assistência Social (BRASIL, 2011, p. 23), o CREAS como uma "unidade pública estatal referência para a oferta de trabalho social a famílias e indivíduos em situação de risco pessoal e social, por violação de direitos, que demandam intervenções especializadas no âmbito do SUAS". Compreende usuários que apesar de terem seus direitos violados, ainda possuem vínculos familiares. Os serviços ofertados pelo CREAS são especificados pela Tipificação Nacional dos Serviços Socioassistenciais (BRASIL, 2009): Serviços de Proteção e Atendimento Especializado a Famílias e Indivíduos (PAEFI); Serviço Especializado em Abordagem Social (SEAS); Serviço de Proteção Social a Adolescente em Cumprimento de Medida Socioeducativa de Liberdade Assistida (LA), Serviços à Comunidade (PSC) e o Serviço de Proteção Social Especial para Pessoas com Deficiência, Idosas e suas Famílias (PCDIF).

Ainda compete a média complexidade o CENTRO POP - Serviço Especializado para Pessoas em Situação de Rua, que se apresenta como um serviço de acolhimento diário que oferece banho, alimentação, atendimento psicossocial e oficinas (SÃO LEOPOLDO/SDS, 2017).

Feitas tais considerações no que se refere ao respectivo nível de atenção, abordaremos com maior profundidade, o serviço no qual a autora se implicou diretamente no estágio, o PAEFI. Consta na Tipificação Nacional dos Serviços Socioassistenciais (BRASIL, 2009 p. 31) o PAEFI como um "serviço de apoio, orientação e acompanhamento a famílias com um ou mais de seus membros em situação de ameaça ou violação de direitos". Portanto, converge para orientações direcionadas à promoção de direitos, a preservação e o fortalecimento de convivência familiar e comunitária e da função protetiva das famílias diante das expressões da questão social que as impactam, que as vulnerabilizam e/ou as submetem a situações de risco pessoal e social. Sendo assim, tem como usuários, famílias e indivíduos que vivenciam violações de direitos por 
ocorrência de "violência física, psicológica e negligência; violência sexual: abuso e/ou exploração sexual; afastamento do convívio familiar devido à aplicação de medida socioeducativa ou medida de proteção"; entre outros (BRASIL, 2009, p. 31).

Trazendo para a realidade de São Leopoldo, a maior parte das famílias atendidas no PAEFI estão em situação de vulnerabilidade em decorrência de abuso sexual das crianças e adolescentes no convívio intrafamiliar, que acabou sendo agravada pelo contexto sanitário da pandemia de Covid-19. O enfrentamento dessa situação de violência contra crianças e adolescentes é atendida pela equipe do PAEFI composta no momento por assistentes sociais e psicólogas, que realizam atendimentos psicossociais. Segundo os Parâmetros para Atuação de Assistentes Sociais na Política de Assistência Social (CFESS, 2011) às abordagens profissionais somam-se assegurando uma intervenção interdisciplinar capaz de responder a demandas individuais e coletivas, que defendem a construção de uma sociedade livre de todas as formas de violência. Nessa perspectiva, o atendimento do CREAS através do PAEFI busca romper com práticas sociais de violência, capazes de minimizar os danos e fortalecer a convivência familiar e comunitária, voltada ao combate ao abuso sexual.

\section{O GRUPO COMO INSTRUMENTO DE TRABALHO DO ASSISTENTE SOCIAL NO SERVIÇO DE PROTEÇÃO E ATENDIMENTO ESPECIALIZADO A FAMÍLIAS E INDIVÍDUOS}

Destaca-se a partir da experiência teórico e prática oriunda dos Estágios em Serviço Social I e II, realizados no CREAS, o grupo como o principal instrumento executado a partir do projeto de intervenção. Diante disso, apresentaremos o processo de trabalho para a realização do grupo "Conversando sobre abuso sexual", bem como a análise crítica desta intervenção, e sua intencionalidade no âmbito da política de Assistência Social.

Essa vivência foi ímpar para compor o Plano de Atendimento Familiar ${ }^{9}$ (PAF) às crianças e adolescentes que encontravam-se no PAEFI por terem vivenciado situação de exploração e abuso sexual.

Iamamoto (2001, p. 20) aponta a possibilidade de "construirmos propostas de trabalho criativas e capazes de efetivar direitos a partir das demandas emergentes no cotidiano". Partindo desse entendimento de que o objeto de trabalho do assistente social

9 Trata-se de instrumental de planejamento, execução, acompanhamento e avaliação das ações desenvolvidas com as famílias. (SÃ̃ PAULO, 2013) 
é a questão social, no respectivo campo de estágio a autora identificou como expressões na vida das participantes do grupo mencionada, as vulnerabilidades decorrentes do abuso sexual. Logo, não se intervém diretamente no abuso sexual, mas sobre a violação de direitos, pois o critério estabelecido pela PNAS para atendimento na média complexidade, operacionalizada pelo CREAS, objetiva a proteção do sujeito em risco social. Ou seja, requer da equipe uma compreensão da história de vida dos usuários para uma proposição condizente as necessidades sociais dos mesmos.

A partir do reconhecimento do objeto, foi preciso definir as estratégias metodológicas a serem adotadas, tidas como "instrumentos ou meios de trabalho que são elementos fundamentais de qualquer processo de trabalho". Uma vez que são eles que potencializam a ação do assistente social sobre seu objeto de trabalho" (Lisboa e Pinheiro, 2005, p. 205).

Para a execução do projeto de intervenção, optou-se pelo grupo, "definido a partir da presença simultânea de indivíduos em uma mesma atividade socioinstitucional coordenada por um ou mais profissionais e que apresente período de duração, objetivos e metodologias definidas" (Moreira, 2019, p 81-82). Tal instrumento possibilitou o atendimento as demandas de forma coletiva, em que uma acolheu a dor, a memória, o relato, umas das outras. Destaca-se que, no que tange as participantes, todas eram do sexo feminino, composta pela mãe e duas filhas, uma criança e uma adolescente em acolhimento institucional; e uma jovem também acolhida. A equipe do CREAS implicada foi composta por uma assistente social, uma psicóloga e a autora na condição de estagiária, naquele ínterim.

Os encontros desse grupo tiveram periodicidade quinzenal, totalizando 4 momentos, através de vídeo chamadas via WhatsApp, contingência enfrentada devida a pandemia do novo coronavírus. Essa estratégia [...] impôs o desafio de pensar quais seriam as atividades que poderiam ser interrompidas ou prestadas sem a presença física de trabalhadores/as, considerando a necessidade do isolamento social" (CFESS, 2020, s/p). Pichon (1998) caracteriza grupo como um conjunto de pessoas, que, ligadas no tempo e espaço e articulada por sua mútua representação interna, propõe-se, em forma explícita ou implícita, a uma tarefa que constitui um objetivo compartilhado entre si.

Foram exibidos vídeos informativos relacionados ao enfrentamento a violência contra crianças e adolescentes. Também, foram discutidos temas como mitos relacionados ao abuso sexual, a violência de gênero, sentimentos vivenciados após o 
abuso, entre outros. Tal discussão propiciou às participantes a escuta de relatos de enfrentamento às violências, repensar possibilidades e o significado das violações em suas vidas. Nessa perspectiva, o projeto de intervenção foi ao encontro do que consta no SUAS a respeito das abordagens grupais tidas como fundamentais, por apresentarem possibilidades de trocas entres os usuários, o respeito às vivências de cada uma, bem como o pertencimento, a conversação dialógica e a ressignificação da violação vivenciada. Vale ressaltar que todos os encontros grupais foram devidamente documentados em relatórios sociais e posteriormente anexados ao prontuário das participantes.

Assim, o foco de intervenção do respectivo projeto deu-se a partir do reconhecimento do objeto de trabalho do assistente social no CREAS, respaldada na apropriação de referenciais teóricos, de saberes relacionado à profissão e o compromisso ético com as usuárias. Através disso, destaca-se a profissão amparada no Código de Ética, ou seja, o exercício profissional condizente com o projeto ético-político para a transformação dessa realidade social.

Essa dimensão foi constatada no processo de trabalho, à medida que, as usuárias (participantes) passaram a se reconhecerem detentoras de direitos e dos canais de denúncia, sobre o fluxo de atendimento na rede de proteção especial do município. Bem como, as mesmas reconhecerem a magnitude das violências perpetradas contra o público infanto juvenil. Acredita-se que com isso, o projeto atendeu sua intencionalidade em prevenir a reincidência de abuso sexual contra essas crianças e adolescentes mediante as reflexões e informações problematizadas no grupo. Ressalta-se que falar de abuso não é tarefa fácil, pois envolve medos, mitos, vergonha e segredos, contudo, as integrantes foram participativas durante toda a abordagem grupal.

Vale ressaltar o quanto foi significativo o resguardo do sigilo e o respeito com a subjetividade de cada uma, o que acabou por contribuir no vínculo entre a autora e as participantes. Por vezes, os relatos de vida de uma acabava se tornando um exemplo para novas perspectivas de vida para a outra, quando uma chorava, a outra a encorajava, criando uma rede de sororidade e fortalecimento mútuo. Diante disso, apontamos como resultados, o empoderamento através da informação assertiva, o fortalecimento das mesmas, bem como os vínculos construídos no grupo e o amadurecimento mediante a dor e sofrimento desencadeados pela violência e violação sofrida. 
A dimensão teórico-metodológica é aquela que permite que o assistente social seja capaz de enxergar a realidade para além da aparência e do senso comum. Nesse sentido, os conhecimentos foram respaldados a partir de autores do Serviço Social e de áreas afins, em especial, na legislação no âmbito da assistência social.

Já a dimensão técnico-operativa enquanto técnicas e instrumentalidade (GUERRA, 2011) apresentaram-se através da escolha dos meios com a intencionalidade para chegar ao fim desejado e que no projeto de intervenção executado deu-se por meio do processo grupal.

As ações interventivas cumpriram com sua intencionalidade, pois propiciaram às adolescentes, jovens e mulheres, ou seja, as participantes do grupo, reflexões acerca do abuso sexual vivenciado e as informações para subsidiá-las na construção de novas perspectivas de vida. Ou seja, para além da violência que sofreram, contribuindo para o fortalecimento de vínculos familiares e comunitários, para que prossigam no caminho na superação do episódio de violência.

\section{CONSIDERAÇÕES FINAIS}

Nota-se que o processo de trabalho de assistentes sociais na política de assistência social, tendo como foco o atendimento às crianças e adolescentes que sofreram violência sexual, através do Serviço de Proteção e Atendimento Especializado a Famílias e Individuos no CREAS, exige um conjunto de conhecimentos, habilidades e atitudes por parte da equipe implicada. Coube ao Serviço Social através do projeto de intervenção apresentado anteriormente, valer-se do grupo como um dos instrumentos para a construção de um espaço coletivo de acolhimento e fortalecimento de vínculos através da escuta sensível e do respeito mútuo frente aos relatos de vida dessas usuárias.

Ressalta-se que o processo de trabalho deu-se em período de pandemia do novo coronavírus, portanto, foi um momento repleto de desafios, mas de aprendizados, e de desenvolvimento da capacidade de reinventar-se. Desse modo, a acadêmica/estagiária se valeu de estratégias metodológicas talvez antes não experienciadas por essa equipe, como o processo grupal em formato remoto. Contudo, os obstáculos trouxeram consigo a necessidade de estabelecimento do novo, essencial para a formação acadêmica e profissional.

Pode-se afirmar que no decorrer das ações interventivas, foi possível desenvolver as competências profissionais, baseando-se no Código de Ética, principalmente, por tratar-se de um tema complexo e íntimo na vida das usuárias do grupo. Nesse período, as 
questões como: Manter o atendimento? Como garantir proteção às vítimas? Será que não vamos colocá-lo em risco novamente? Todas questões que inquietaram a equipe do CREAS e colocaram em risco a intervenção nesse formato de trabalho. Contudo, vale ressaltar o quão necessário foi tal grupo como instrumento de trabalho frente à demanda. Isso possibilitou a troca entre essas usuárias acerca de suas vivências, desenvolvendo o pertencimento, o diálogo e a ressignificação da violação vivenciada. O espaço mostrouse tão necessário, que acabou sendo incorporado no trabalho da equipe, ou seja, na oferta de serviços do CREAS através do PAEFI.

O presente trabalho reafirma a luta e a defesa dos direitos de crianças e adolescentes. Também evidenciou a importância da categoria no combate a violência sexual contra o público infanto juvenil, haja vista o aumento desta violação de direitos em tempos pandêmicos, uma vez que são os espaços socio ocupacionais onde o assistente social está inserido que deve assegurar o atendimento nesse âmbito.

\section{REFERÊNCIAS}

AZEVEDO, M. A.; GUERRA, V. N. A. Mania de bater: a punição corporal doméstica de crianças e adolescentes no Brasil. São Paulo: Iglu, 2001.

BEHRING, Elaine Rosseti. Política social: fundamentos e história / Elaine Rossetti Behring, Ivanete Boschetti. - 9. ed. - São Paulo: Cortez, 2011. - (Biblioteca básica de serviço social; v. 2)

BRASIL. Código de Ética do/a Assistente Social. Lei 8.662/93 de regulamentação da profissão. - 10o ed. rev. e atual. - [Brasília]: Conselho Federal de Serviço Social, 2012.

BRASIL. [Constituição (1988)]. Constituição da República Federativa do Brasil de 1988. Brasília, DF: Presidência da República, [2020]. Disponível em:

http://www.planalto.gov.br/ccivil_03/constituicao/constituicao.htm. Acesso em: 03 out. 2021.

BRASIL. Lei no 8.069, de 13 de julho de 1990. Dispõe sobre o Estatuto da Criança e do Adolescente e dá outras providências. Diário Oficial [da] República Federativa do Brasil, Brasília, DF, 16 jul.

BRASIL. Política Nacional de Assistência Social - PNAS/2004; Norma Operacional Básica - NOB/Suas. Brasília: Ministério do Desenvolvimento Social e Combate à Fome - Secretaria Nacional de Assistência Social, 2005.

BRASIL. Lei n8742/93. Lei Orgânica de Assistência Social - LOAS. Brasília 1993.

BRASIL, Ministério do Desenvolvimento Social e Combate à Fome. Secretaria Nacional de Assistência Social. Orientações Técnicas sobre o PAIF. O Serviço de 
Proteção Integral à Família segundo a Tipificação Nacional de Serviços Socioassistenciais. Volume I. Brasília: MDS, 2012.

BRASIL, Ministério do Desenvolvimento Social e Combate à Fome. Secretaria Nacional de Assistência Social. Tipificação Nacional de Serviços Socioassistenciais. Brasília: MDS, 2009.

BRASIL, Ministério de Desenvolvimento Social e Combate à Fome. Orientações técnicas: Centro de Referência Especializado de Assistência Social - CREAS. Brasília, 2011.

CFESS, Conselho Federal do Serviço Social. Parâmetros para a Atuação de Assistentes Sociais na Política de Assistência Social. CFESS. Brasília, 2011. Disponível em: http://www.cfess.org.br/arquivos/Cartilha_CFESS_Final_Grafica.pdf

FALEIROS, V.P; FALEIROS, E.S. Escola que Protege: enfrentando a violência contra crianças e adolescentes. Coleção Educação para Todos:31. MEC/SECADI. BrasíliaDF. 2007. 101p.

FISCHER, Rosa Maria Retratos dos direitos da criança e do adolescente no Brasil : pesquisa de narrativas sobre a aplicação do ECA / Rosa Maria Fischer, Luana Schoenmaker; colaboradores Graziella Maria Comini...[et al.]. -- São Paulo : Ceats/FIA, 2010. $48 \mathrm{p}$

GIL, Antônio Carlos. Como elaborar projetos de pesquisa. 4 ed. São Paulo, SP: Atlas, 2002.

GUERRA, Yolanda. A Instrumentalidade do Serviço Social. São Paulo: Cortez, 2011.

IAMAMOTO, Marilda Villela. Serviço Social em Tempo de Capital Fetiche: Capital Financeiro, Trabalho e Questão Social. $9^{\circ}$ E.d. São Paulo. Cortez. 2015.

IAMAMOTO, Marilda Villela. O Serviço Social na contemporaneidade: trabalho e formação profissional. São Paulo: Cortez, 1998 e 2001.

IBGE - INSTITUTO BRASILEIRO DE GEOGRAFIA E ESTATÍSTICA. Cidades: São Leopoldo/ Rio Grande do Sul/ RS. In IBGE, 2021. Disponível em: https://cidades.ibge.gov.br/brasil/rs/sao-leopoldo/panorama.

LAKATOS, Eva Maria; MARCONI, Marina de Andrade. Técnicas de pesquisa: planejamento e execução de pesquisas, amostragens e técnicas de pesquisas, elaboração, análise e interpretação de dados. 5. ed. São Paulo: Atlas, 2002.

LIRA, M. O. S. C. e et al. (2017). Abuso sexual na infância e suas repercussões na vida adulta. Texto contexto - Revista de Enfermagem, Florianópolis, v. 26, n. 3. Disponível em: https://www.scielo.br/j/tce/a/Fq8Cg6 F7bcbZRNhxFqKTMTR/

LISBOA, T., PINHEIRO, E. A intervenção do serviço social junto à questão da violência contra a mulher. Katálysis, Florianópolis, v. 8, n. 2, jul./dez. 2005.

LOPES, Maria Suzete Muller. Fundamentação Crítica do Processo de Trabalho. In: Processo de Trabalho no Serviço Social. Canoas. Ed. Ulbra, 2010.

MINAYO, M. C. S. Amostragem e Saturação em Pesquisa Qualitativa: consensos e 
controvérsias. Revista Qualitativa, v. 5, n. 7 (abril), p. 01-12, 2017.

MINAYO, M. C. S.; DESLANDES, S. F . Pesquisa social: teoria, método e criatividade. 25. ed. rev. atual. Petrópolis: Vozes, 2007. 108p.

MINAYO, M.C. S. Violência: um problema para a saúde dos Brasileiros. IN: Impactos da Violência na Vida dos Brasileiros. Ministério da Saúde / Secretaria de Vigilância em Saúde. Brasília-DF. 2005. Disponível em http://bvsms.saude.gov.br/bvs/ publicacoes/impacto_violencia.pdf .

MOREIRA, Carlos Felipe Nunes. O Trabalho com Grupos em Serviço Social: a dinâmica de grupo como estratégia para reflexão crítica. 5a ed, São Paulo. Cortez Editora. 2019.

RIZZINI I, PILOTTI F, organizadores. A arte de governar crianças. Rio de Janeiro: Amais, Santa Úrsula; 1996.

SILVA, Ângela Maria Pereira da. Instrumentalidade e instrumentais técnicos do serviço social/ Ângela Maria Pereira da Silva. Curitiba: InterSaberes, 2017. (Série Formação Profissional em Serviço Social).

SIQUEIRA, Andreia Conceição. Serviço Social e Violência Sexual: Reflexões a partir do trabalho da rede de atenção a violência sexual de Diadema. Pontifícia Universidade Católica de São Paulo. São Paulo: 2009. 